УДК 629.4.083

\title{
ОЦІНКА ВПЛИВУ ВІДХИЛЕНЬ ЕКСПЛУАТАЦІЙНИХ І РОБОЧИХ ХАРАКТЕРИСТИК ОБЛАДНАННЯ НА ЇХ НАДІЙНІСТЬ
}

Д-р техн. наук О. С. Крашенінін

\section{ОЦЕНКА ВЛИЯНИЯ ОТКЛОНЕНИЙ ЭКСПЛУАТАЦИОННЫХ И РАБОЧИХ ХАРАКТЕРИСТИК ОБОРУДОВАНИЯ НА ЕГО НАДЕЖНОСТЬ}

Д-р техн. наук А. С. Крашенинин

\section{ASSESSMENT OF INFLUENCE OF DEVIATIONS OF OPERATIONAL AND PERFORMANCE DATA OF THE EQUIPMENT ON ITS RELIABILITY}

Doct. of techn. Sciences A. S. Krasheninin

Погіршення технічного стану експлуатуємого локомотивного парку залізниць вимагає від локомотивного господарства значних зусиль щэодо забезпечення ефективності його використання.

Для реалізації иієєї задачі при сучасному стані ТРС, зокрема, запропонована методика оцінки впливу відхилень експлуатаційних і робочих характеристик обладнання на надійність несучих конструкиій для коректування технологї̈ їх утримання, за рахунок проведення комплексних заходів з підтримки і забезпечення їх властивостей з часом експлуатації.

Ключові слова: експлуатаційні і робочі характеристики обладнання; надійність; локомотивний парк; несучі конструкиії.

Ухудшение технического состояния, эксплуатируемого локомотивного парка железных дорог, требует от локомотивного хозяйства значительныле усилия по обеспечению эффективности его использования.

Для реализации этой задачи при современном состоянии ТРС, в частности, предложенная методика оченки влияния отклонений эксплуатационных и рабочих характеристик оборудования на надежность несущих конструкиий для корректировки 
технологии их содержания, за счет проведения комплексных соответствуюших мер по поддержанию и обеспечению их свойств со временем эксплуатации.

Ключевые слова: эксплуатационные и рабочие характеристики оборудования; надежность; локомотивный парк; несущие конструкции.

The locomotive park, is operated on the railroads of Ukraine, reached the deadline of use and its technical condition comes nearer to the critical. In operation it isn't possible to provide planned frequency and volume of maintenance and repair which is forcedly carried out and it is spontaneous, corresponds to the differentiated principles more and more, that is it is carried out depending on technical condition of the locomotive necessarily.

Complexity of the solution of this task is that formalization its rather difficult and is connected with questions of economic, physical and mathematical aspect

In these conditions compulsory measures of Ukrzaliznytsi are directed on justification and ensuring actions for extension of term of operation of locomotives. In turn it defines need of scientific justification of terms and actions which are capable to ensure efficiency and safety of work of locomotive park.For this problem at the present state of traction rolling stock, including the technique of assessing the impact of deviations operational performance and equipment reliability to their supporting structures to adjust their maintenance technology, by conducting comprehensive response to support and ensure their properties over time operation.

Keywords: performance and the performance of the equipment; reliability; Locomotive Park; supporting structures.

Вступ. Локомотивний парк, що експлуатується на залізницях України, досягнув свого граничного терміну використання $\mathrm{i}$ його технічний стан наближається до критичного. В експлуатації не вдається забезпечити планову періодичність і об'єм технічного обслуговування i ремонту яка вимушено проводиться і стихійно все більше відповідає диференційованим принципам, тобто проводиться в залежності від технічного стану локомотиву по потребі.

Складність вирішення цієї задачі полягає в тому, що формалізація іiі досить складна i пов'язана 3 питаннями економічного, фізичного i математичного аспекту[1,2].

\section{Постановка}

\section{проблеми}

загальному вигляді та іï зв'язок із важливими науковими та практичними завданнями. Сучасний стан локомотивного господарства залізниць вимагає значних зусиль на підтримку ефективності його використання.

В цих умовах вимушені заходи Укрзалізниці направлені на обгрунтування і забезпечення заходів 3 подовження терміну експлуатації локомотивів. В свою чергу це визначає необхідність наукового обгрунтування термінів і заходів, які спроможні забезпечити ефективність і безпеку роботи локомотивного парку.

Аналіз останніх досліджень i публікацій. Питанням визначення та поліпшення техніко-економічних показників функціювання тягового рухомого складу, впровадження ресурсозберігаючих технологій приділяється багато уваги, як експлуатаційниками, так і науковцями.

Розробці i розвитку основних принципів теорії надійності, оптимізації технічного обслуговування i ремонту рухомого складу присвячені зокрема роботи Тартаковського Е.Д., Фалендиша А.П., Басова Г.Г., Дьоміна Ю.В., Устенка О.В. та інших вчених.

Визначення мети та задачі дослідження. Обгрунтування чинників, що забезпечують ефективність підтримки технічного стану несучих конструкцій шляхом проведення комплексу заходів по їх утриманню.

Основна частина дослідження. При створенні несучих конструкцій локомотивів основним заходом щодо забезпечення надійності механічних конструкцій зазвичай використовується запас міцності, який визначається як відношення властивостей несучої спроможності конструкції до середніх експлуатаційних навантажень. 
Розрахунковий запас міцності містить у собі деяку невизначеність щодо методів розрахунку несучої спроможності та експлуатаційних навантажень i запасу на розсіювання цих величин. Границі запасу міцності визначаються з досвіду експлуатації аналогічних конструкцій, тому далеко не завжди можна стверджувати, що конструкція 3 більшим запасом міцності більш надійна конструкції з меншим запасом міцності, особливо якщо мова йде про різні конструкції, що експлуатуються в різних умовах.

Останнім часом усе більше поширення одержує імовірнісний підхід до розрахунків механічних конструкцій, оцінка надійності роботи яких проводиться за критеріями, прийнятим у теорії надійності, а саме поняття «запас міцності» набуває нового сенсу.

Розглянемо насамперед питання щодо розрахунку міцності якого-небудь елемента механічної конструкції. При цьому елемент у загальному випадку повинен задовольняти двом вимогам:

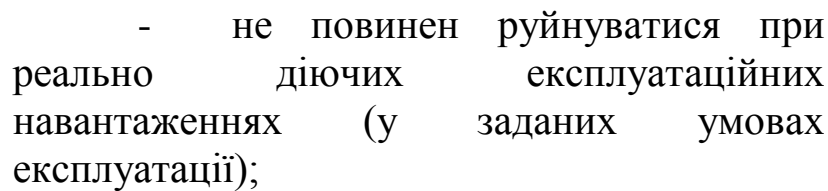

- деформації його не повинні перевищувати заданих величин.

У відповідності із цим слід розглядати такі граничні стани конструкції:

руйнується);

- по міцності (конструкція

- по деформації (конструкція досягає неприпустимі деформації).

Відповідно до цього розрізняють експлуатаційні навантаження, що діють на конструкцію $(E)$, і несучу спроможність конструкції по міцності - руйнівне навантаження $(R)$ і по деформації $(Q)$.

3 досвіду експлуатації відомо, що як несуча спроможність, так і експлуатаційні навантаження на несучі конструкції локомотивів $€$ випадковими величинами. Причинами, що викликають розсіювання несучої спроможності, $є$ :

\section{розсіювання}

характеристик механічних властивостей матеріалу елемента конструкції; розсіювання

геометричних

розмірів елементів конструкцій.

Коливання геометричних розмірів технічного об'єкту визначаються класом точності виготовлення.

Коливання

експлуатаційних навантажень залежать від умов, у яких експлуатується технічний об'єкт, і можуть досягати значних величин[5,11].

Вирази для розрахунків несучої спроможності по міцності і по деформації різняться залежно від виду навантаження, однак у загальному випадку їх можна записати таким чином

$$
\begin{aligned}
& R=\sigma \prod_{i=1}^{I} x_{i}^{n_{i}} \\
& Q=E_{M} \prod_{i=1}^{I} x_{i}^{m_{i}},
\end{aligned}
$$

де $x_{i}-$ геометричні розміри елементів конструкції (або їх суми);

$E_{M}-$ модуль пружності; $\sigma \quad-$ допустиме напруження.

Оскільки несуча спроможність являє собою добуток випадкових величин, тому остаточне рішення питання про закон розподілу несучої спроможності пов'язане 3 певними труднощами. Загальним методом визначення цього закону в відповідних випадках може бути метод статистичних випробувань, у результаті застосування якого отримують для кожного конкретного випадку щільність розподілу несучої спроможності [3]

$$
\begin{aligned}
& \varphi(R)=\varphi(R, M, K) ; \\
& \varphi(Q)=\varphi(Q, M, K),
\end{aligned}
$$

де $M$ - матеріал, 3 якого виготовлений елемент конструкції. Він характеризується законами розподілу величин $\sigma \mathrm{i} E_{M}$;

$K$ - якість виготовлення, що характеризується законом розподілу розмірів $x_{i}$.

Однак у більшості випадків, що зустрічаються у практиці, приймаються закон розподілу несучої спроможності нормальним, а його параметри визначають одним з наближених методів [4].

У якості найбільш простого, але наближеного методу можна рекомендувати 
метод наведених збурювань, алгоритм якого полягає у наступному.

Обчислюємо

$$
R_{0}=\sigma_{0} \prod_{i=1}^{I} x_{i_{0}}^{n_{i}},
$$

де індексом «0» позначені математичні очікування;

$\left.\sigma_{R}=B \mid R_{0}-R\left(\sigma_{0} \pm \sigma_{\sigma} ; x_{10} \pm \sigma_{x_{1}} ; \ldots ; \sigma_{I 0} \pm \sigma_{x I}\right)\right]$,

тут знаки при $\sigma(i=0, l)$ упорядковані таким чином, щоб $\sigma_{R}$ убувало. Величина $B$ дорівнює

$$
B=\frac{\sqrt{1+\frac{\pi}{2} I}}{1+I}
$$

Метод заснований на вивченні розподілу випадкових величин

$$
B=\frac{\sqrt{\sum_{i=1}^{I} x_{i}^{2}}}{\sum_{i=1}^{I} x_{i}}
$$

i на гіпотезі розподілі величин $x_{i}$ як модулів нормально розподілених $[6,7]$.

Наближеним методом визначення $x_{i}$ може бути метод часток похідних, згідно 3 яким

$$
\sigma_{R} \cong \sqrt{\left(\frac{\partial R}{\partial \sigma} \sigma_{\sigma}\right)^{2}+\sum_{i=1}^{I}\left(\frac{\partial R}{\partial \sigma} \sigma_{i}\right)^{2}} .
$$

У загальному випадку критерієм механічної надійності елемента конструкції $\epsilon$ ймовірність його безвідмовної роботи, тобто відсутності обох граничних станів,

$$
P=\operatorname{Bep}(R-E>0 ; Q-E>0)=\int_{0}^{\infty} \int_{0}^{\infty} \varphi(R-E ; Q-E) d(R-E) d(Q-E)
$$

У тих випадках, коли $R$ і $E$ можна вважати розподіленими за нормальним нормальним законом

$$
\begin{gathered}
P=\int_{0}^{\infty} \frac{1}{\sigma_{R-E} \sqrt{2 \pi}} \exp \left[-\frac{1}{2}\left(\frac{E-R-E_{0}+R}{\sigma_{R-E}}\right)\right]^{2} d(R-E)= \\
=F_{0}\left[\frac{R_{0}-E_{0}}{\sqrt{\sigma_{R}^{2}+\sigma_{E}^{2}-2 \rho_{R E^{\sigma} R^{\alpha} E}}}\right],
\end{gathered}
$$

де $R_{0}$ i $E_{0}-$ математичні очікування несучої спроможності та експлуатаційного навантаження; відхилення цих величин;

$$
\sigma_{R} \text { i } \sigma_{E}-\text { середньоквадратичне }
$$

$\rho_{R E}-$ коефіцієнт кореляції між ними;

$$
P=F_{0}\left(\frac{\eta_{0}-1}{\sqrt{\eta_{0}^{2} v_{R}^{2}+v_{E}^{2}}}\right)=\Phi_{0}\left(\frac{\eta_{0}-1}{\sqrt{\eta_{0}^{2} v_{R}^{2}+v_{E}^{2}}}\right)+0,5,
$$

де $\eta_{0}=\frac{R_{0}}{Э_{0}} ; v_{R}=\frac{\sigma_{R}}{R_{0}}$ i $v_{E}=\frac{\sigma_{E}}{E_{0}}$;

$\eta_{0}$ - умовний запас міцності; $v_{R}$ i $v_{E}-$ коефіцієнти варіації навантажень;

$\Phi_{0}$ - функція Лапласа.

Критеріально ефективності заходів надійності конструкцій доцільно проводити 3 урахуванням зусиль (витрат) на ці заходи. Відповідно до цього розглянемо питання про вибір оптимальної надійності механічної конструкції. Нехай вартість витрат на забезпечення надійності визначається таким чином 


$$
C=\frac{C_{1}}{P}+C_{2}(1-P),
$$

де $C_{1}-$ витрати (вартість) на створення технічного об'єкту (механічної конструкції);

$C_{2}$ - додаткові витрати, викликані відмовою технічного обладнання в процесі експлуатації.

Вартість технічного об'єкту можна оцінити з залежності

$$
C_{1}=\bar{C}(\bar{a}, \sigma, \bar{X}),
$$

де $\bar{a}-$ витрати на доставку, можливого технічного об'єкту;

$$
\bar{X} \text { - вектор геометричних розмірів } 3
$$

компонентами $x_{1}, x_{2}, \ldots, x_{i}, \ldots, x_{I}$.

При відомих $E_{0}, v_{E}, v_{R}$ завдання ознаки оптимальної надійності механічної конструкції технічного об'єкту формулюється таким чином.

Необхідно задані параметри $\sigma$ i $\bar{X}$ підібрали таким чином, щоб мінімізувати $C$ (13) при наявності зв'язків (7), (12) і (14). Залежно від виду конкретних залежностей це завдання вирішуватися одним 3 методів математичного програмування [7-9].

Отримання оптимальних витрат $C$ залежить від значень $P=f\left(\eta_{0}, v_{R}, v_{E}\right)$, які можуть приймати в експлуатації широкий спектр значень.

Звідси потрібно визначити такі $\eta_{0}, v_{R}, v_{E}$, при яких сумарна вартість $C$ досягатиме мінімуму. $\mathrm{У}$ цьому випадку заданих значень $\eta_{0}$ пошуки $\min C$ при фіксуванні $v_{R}$ i $v_{E}$ легко реалізуються за допомогою будь-якого чисельного методу відшукання екстремуму.

Визначимо оптимальну величину запасу міцності несучих конструкцій (НК) при різних відносних витратах від $C / C_{1} \cdot$ i $C_{2} / C_{1}$, задаючись коефіцієнтами варіації від $v_{R}=0,1 \div 0,3$ i $v_{E}=0,1 \div 0,3$.

В таблиці 1 приведені розрахунки визначення приведеної вартості $C / C_{1}$ при значеннях $v_{R}=0,1, v_{E}=0,1$ в залежності від $\eta_{0}$. На підставі варіювання параметрів $v_{R} \mathrm{i}$
$\begin{array}{lll}v_{E} & \text { визначено діапазон зміни }\end{array}$

$C / C_{1}=f\left(\frac{C_{2}}{C_{1}}, \eta_{0}, v_{R}=\right.$ const,$v_{E}=$ const $), \quad$ що приведені на рис.1.

Висновки 3 дослідження i перспективи, подальший розвиток у даному напрямку.

1. Зростання коефіцієнту $\eta_{0}$ при будь-якому співвідношенні $C_{2} / C_{1}$ дозволяє зменшувати приведені сумарні витрати на утримання несучих конструкцій до деяких границь.

2. Тільки за умови дотримання значень $v_{0}: v_{R} \leq 0,1$ вдається отримати $\min C / C_{1}$, причому при рості $C_{2} / C_{1}$ необхідно забезпечувати більший запас міцності $\eta_{0}$. При $C_{2} / C_{1} \leq 10$ мінімальне значення $C / C_{1}$ досягається при $\eta_{0}=1,4$, а при $C_{2} / C_{1}>10$ мінімум $C / C_{1}$ забезпечується при зростанні $\eta_{0}$

3. Значне коливання коефіцієнтів варіації $v_{R}$ i $v_{E}$ навіть при високому рівні надійності $\left(\eta_{0}>1,5\right)$ не забезпечує досягнення $\min C / C_{1}$. Тобто підтверджують дані експлуатації, що при рості приведених витрат за нормативний термін експлуатації ТРС $\left(C_{2}\right)$ для досягнення високої надійності необхідно проводити заходи, що направлені на підтримку стабільності $\eta_{0}$ за рахунок технологічних засобів зміцнення ризикових зон несучих конструкцій.

4. При сучасному стані ТРС при коректуванні терміну його життєвого циклу, слід застосовувати моніторинг технічного стану несучих конструкцій шляхом діагностування i проведення відповідних заходів 3 підтримки, забезпечення їх властивостей з часом експлуатації. 
Таблиця 1

\begin{tabular}{|c|c|c|c|c|c|c|c|c|c|}
\hline \multicolumn{2}{|r|}{$\eta_{0}$} & 1,0 & 1,1 & 1,2 & 1,3 & 1,4 & 1,5 & 1,6 & 1,7 \\
\hline \multicolumn{2}{|r|}{$C_{1}$} & 1 & 1,1 & 1,2 & 1,3 & 1,4 & 1,5 & 1,6 & 1,7 \\
\hline \multicolumn{2}{|r|}{$\eta_{0}-1$} & 0 & 0,1 & 0,2 & 0,3 & 0,4 & 0,5 & 0,6 & 0,7 \\
\hline \multicolumn{2}{|r|}{$\eta_{0}^{2} v_{R}^{2}$} & 0,0100 & 0,0121 & 0,0144 & 0,0169 & 0,0196 & 0,0225 & 0,0256 & 0,0289 \\
\hline \multicolumn{2}{|c|}{$\eta_{0}^{2} v_{R}^{2}+v_{\ni}^{2}$} & 0,0200 & 0,0221 & 0,0244 & 0,0269 & 0,0296 & 0,0325 & 0,0356 & 0,0389 \\
\hline \multicolumn{2}{|c|}{$\sqrt{\eta_{0}^{2} v_{R}^{2}+v_{\ni}^{2}}$} & 0,141 & 0,149 & 0,156 & 0,164 & 0,172 & 0,180 & 0,189 & 0,197 \\
\hline \multicolumn{2}{|c|}{$x=\frac{\eta_{0}-1}{\sqrt{\eta_{0}^{2} v_{R}^{2}+v_{\ni}^{2}}}$} & 0,00 & 0,67 & 1,28 & 1,83 & 2,32 & 2,77 & 3,18 & 3,55 \\
\hline \multicolumn{2}{|c|}{$P=F_{0}(x)$} & 0,500 & 0,749 & 0,900 & 0,9664 & 0,9901 & 0,9973 & 0,9993 & 0,9998 \\
\hline \multicolumn{2}{|c|}{$1-F_{0}(x)$} & 0,500 & 0,251 & 0,100 & 0,0336 & 0,0099 & 0,0027 & 0,0007 & 0,0002 \\
\hline \multirow{2}{*}{$\begin{array}{l}C_{2}=10 \\
\left(C_{2} / C_{1}\right)\end{array}$} & $y=C_{2}\left[1-F_{0}(x)\right]$ & 5 & 2,28 & 0,83 & 0,26 & 0,07 & 0,018 & 0,004 & 0,001 \\
\hline & $C=C_{1}+C_{2}$ & 6 & 3,38 & 2,03 & 1,56 & 1,47 & 1,52 & 1,60 & 1,7 \\
\hline \multirow{2}{*}{$\begin{array}{l}C_{2}=20 \\
\left(C_{2} / C_{1}\right)\end{array}$} & $y=C_{2}\left[1-F_{0}(x)\right]$ & 10 & 4,56 & 1,67 & 0,52 & 0,14 & 0,036 & 0,008 & 0,002 \\
\hline & $C=C_{1}+C_{2}$ & 11 & 5,66 & 2,87 & 1,82 & 1,54 & 1,536 & 1,60 & 1,7 \\
\hline \multirow{2}{*}{$\begin{array}{l}C_{2}=50 \\
\left(C_{2} / C_{1}\right)\end{array}$} & $y=C_{2}\left[1-F_{0}(x)\right]$ & 25 & 11,4 & 4,17 & 1,29 & 0,35 & 0,09 & 0,02 & 0,005 \\
\hline & $C=C_{1}+C_{2}$ & 26 & 12,5 & 5,37 & 2,59 & 1,75 & 1,59 & 1,62 & 1,70 \\
\hline
\end{tabular}

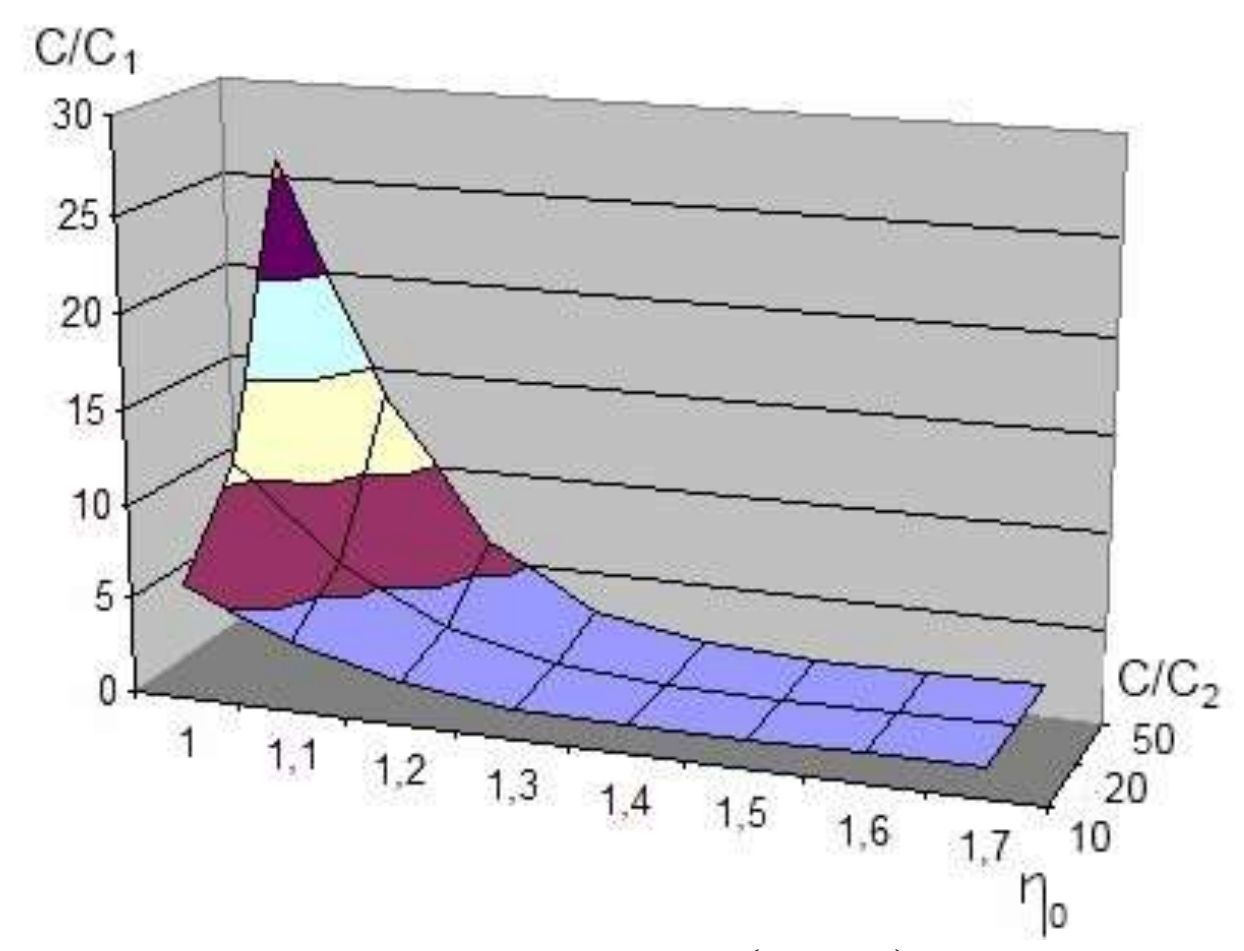

Рис. 1 Зміна приведених витрат $C / C_{1}=f\left(\eta_{0}, C_{2} / C\right)$ при $V_{R}=0,1$ і $V_{E}=0,1$

\section{Список використаних джерел}

2. Тартаковский, Э.Д. Методы оценки жизненного цикла тягового подвижного состава железных дорог: Монография / Э.Д. Тартаковский, С.Г. Грищенко, Ю.Е. Калабухин, 
А.П. Фалендыш. - Луганск: Изд-во «Ноулидж», 2011. - 174 с. Ил. 63, табл. 12, список лит. 191 наим.

3. Сухарев, Э.А. Теория эксплуатационной надежности машин / Лекционный курс. - Рівне: Видавництво УДАВГ, 1997, 162 с.

4. Степнов, М.Н. Статистические методы обработки результатов механических испытаний / Справочник. - М.: Машиностроение, 1985. - 232 с.

5. Галкин, В.Г. Надежность тягового подвижного состава. / В.Г.Галкин, В.П. Парамзин, В.А. Четвергов. Учеб. пособие для вузов ж.-д. трансп. // М.:Транспорт, 1981, 184c.

6. Северцев Н.А. Надежность сложных систем в эксплуатации и отработке: Учеб. пособие для вузов. - М.: Высш. шк., 1989. - 432с.

7. Решетов, Д.Н. Надежность машин / Д.Н. Решетов, А.С. Иванов, В.3. Фадеев. М.: Высш. шк., 1988.

8. Козлов, Б.А. Справочник по расчету надежности аппаратуры радиоэлектроники и автоматики [Текст] Б.А. Козлов, И.А. Ушаков // М.: Изд-во «Советское радио», 1975. - 472с.

9. $\quad$ Гуров С.В., Уткин Л.В. Надежность систем при неполной информации. - СПб.: Любавич, 1999, 160 с.

10. Диллон Б., Сингх Ч. Инженерные методы обеспечения надежности систем. М.: Мир, 1984, 318 с.

11. Костецкий Б.И. и др. Надежность и долговечность машин. - Киев: Техника, 1975,408 c.

12. Пронников А.С. Надежность машин. - М.: Машиностроение, 1978, 592 с.

Крашенінін Олександр Семенович, д-р техн. наук, професор кафедри «Експлуатація та ремонт рухомого складу», Українська державна академія залізничного транспорту. Тел. (057)) 730 19 99. Еmail:info@kart.edu.ua.

Krasheninin Oleksandr Semenovich d-r science, professor department. "Operation and Repair of Rolling Stock" Ukrainian State Academy of Railway Transport. Tel. (057)730-19-99.

E-mailinfo@kart.edu.ua. 